\title{
UPAYA SANTRI DALAM PEMELIHARAAN \\ HAFAL AL- QUR'AN DI MANU KOTA GEDE YOGYAKARTA
}

\author{
Ahlan Abdullah Solo \\ Alumni FAI UCY \\ Taufik Nugroho \\ FAI UCY \\ Difla Nadjih \\ FAI UCY
}

\begin{abstract}
Abstrak: penelitian yang bertujuan untuk mengetahui pelaksanaan metode muraja'ah dalam hafalan Al-Qur'an di Madrasah Aliyah Nurul Ummah Kotagede Yogyakarta (MANU) agar bisa diidentifikasi faktor pendukung dan penghambat yang dialami oleh para santri termasuk bagaimana mereka mengatasi factor penghambatnya. Siswa santri MANU selalu melakukan muraja'ah hafalan Qur'an dengan target tiap hari adalah satu halaman tanpa menghitung berapa ayat yang dihafalkan. Metode itu bermanfaat untuk menjaga hafalan Al-Qur'an dan tidak mengganggu kegiatan belajar mengajar di pesantren.
\end{abstract}

Kata kunci: muroja'ah, hafalan, santri

Abstact: The research aimed to find out the implementation of the Muraja'ah method in memorizing Al-Qur'an in Kotagede Yogyakarta's Aliyah Nurul Ummah Madrasah (MANU) in order to identify the supporting and inhibiting factors experienced by the santri including how they overcome the inhibiting factors. MANU santri students always do the Koran memorization with a target every day is one page without counting how many verses are memorized. The method is useful for maintaining memorization of the Qur'an and does not interfere with teaching and learning activities in boarding schools.

Keywords: muroja'ah, memorizing, student

\section{A. Pendahuluan}

Dalam proses hafal al-Quran, Muroja'ah adalah proses yang amat penting. Muraja'ah adalah mengulang bacaan ayat atau surat yang telah dihafalkan dengan baik. ${ }^{1}$ Penerapannya secara kontinyu akan menguatkan hafalan, menghafal secara kontinyu itu lebih penting dan itulah hakikat dari menghafal. Hadis yang menguatkan hal itu sebagai berikut; "Jika

1 Bahirul Amalia Herry, Agar Orang Sibuk Bisa Menghafal Al-Qur'an (Kelompok Penerbit Pro-U Media), Ha. 154 
seorang penghafal Al-Qur'an shalat lalu ia membacanya pada malam dan siang hari, niscaya ia akan senantiasa mengingatnya. Namun, jika ia tidak melakukannya hal itu, niscaya ia akan melupakannya" 2

Untuk itulah perlu penelitian yang bertujuan untuk mengetahui pelaksanaan metode muraja'ah dalam menghafal Al-Qur'an untuk mengetahui faktor pendukung dan penghambat dalam pelaksanaannya dan bagaimana mereka mengatasi factor penghambatnya. Semua itu dilakukan di Madrasah Aliyah Nurul Ummah Kotagede Yogyakarta (MANU).

Instrument pengumpulan Penelitian ini menggunakan angket selain observasi dan wawancara mendalam. Metode angket dalam penelitian ini digunakan untuk mengumpulkan data tentang pelaksanaan metode muraja'ah dalam menghafal Al-Qur'an, faktor penukung dan penghambat dalam pelaksaan metode muraja'ah serta solusi untuk mengatasi faktor penghambat pelaksanaan metode muraja'ah dalam menghafal Al-Qur'an. Dengan metode wawancara, peneliti akan melakukan wawancara dengan Kepala Madrasah Aliyah, ustadz/guru dan siswa-siswi dalam kegiatan menghafal Al-Qur'an dengan metode muraja'ah di MANU.

\section{B. Faktor Pendukung dan Penghambat Hafal Al-Qur'an}

1. Faktor Pendukung Pelaksanaan Metode Muraja'ah dalam Menghafal Al-Qur'an

a. Sudah lancar membaca Al-Qur'an

Dalam menghafal hafalan Al-Qur'an santri-siwi tentunya harus sudah lancar dalam membaca Al-Qur'an. Jikalau belum lancar membaca Al-Qur'an maka sungguh sangat sulit ketika menghafal Al-Qur'an, bisa juga secara logika dapat kita katakana bahwa membaca Al-Qur'an saja tidak bisa apalagi menghafalkannya, sunnguh sangat ironis jikalau santri yang mau menghafal Al-Qur'an belum bisa membaca Al-Qur'an dan adapun sebagian dari kita menggunakan tulisan bahasa Indonesia.

${ }^{2}$ Majdi Ubaid Al-Hafizh, 9 Langkah Mudah Menghafal Al-Qur'an, ( PT Aqwaf Media Profetika, Solo 2015).hal...142 


\section{Upaya Santri Dalam Pemeliharaan Hafal Al- Qur'an}

Di MANU Kota Gede Yogyakarta

Berdasarkan angket yang penulis bagikan santri pada umumnya sebagian besarsiwa-siswi sudah mampu membaca Al-Qur'an.

b. Memiliki Sifat Sabar

Sabar merupakan kunci kesuksesan untuk meraih cita-cita, termasuk cita-cita dan keinginan untuk menghafal Al-Qur'an. Kesulitan akan dihadapi jika tidak mempunyai sifat sabar dalam menghafal AlQur'an. Oleh karena itu, seorang hafidz tidak boleh mengeluh dan patah semangat ketika mengalami kesulitan dalam proses bermuraja'ah hafal AlQur'an. Dibawah ini adalah hasil angket tentang kesabaran seorang ketika bermuraja'ah hafalan Al-Qur'an.

c. Motivasi dari orang-orang tendekat seperti Ustadz/guru

Orang yang menghafal Al-Qur'an, pasti sangat membutuhkan motivasi dari orang-orang terdekat, Ustadz/Ustadzah tentunya. Dengan adanya motivasi, ia akan lebih bersemangat dalam menghafalkan AlQur'an. Tentunya, hasil yang diperoleh akan berbeda jika motivasi yang didapatkan kurang. Berdasrkan angket yang dibagi, dibawah ini adalah hasil angket tentang motivasi Ustadz/Ustadzah, sebagai berikut :

d. Muraja'ah Hafalan Al-Qur'an dalam Shalat Sunnah

Diantara penghafal Al-Qur'an ada memproses hafalannya secara spesifik, yakni tidak ada kesibukan lain kecuali menghafal Al-Qur'an saja. Ada pula yang menghafal disamping juga melakukan kegiatan-kegiatan lain. Seorang penghafal harus mampu mengantisipasi dan memilih waktu yang dianggap sesuai dan tepat baginya untuk menghafal Al-Qur'an. Para psikolog mengatakan, bahwa manajemen waktu yang baik akan berpengaruh besar terhadap pelekatan materi pada ingatan, utamanya dalam hal ini bagi mereka yang mempunyai kesibukan lain. Dalam memenej waktu yang. Dibawah ini adalah hasil angket tentang meluang kan waktu untuk muraja'ah hafalan Al-Qur'an dalam shalat sunnah.

2. Faktor Penghambat Pelaksanaan Metode Muraja'ah dalam Menghafal Al-Qur'an di MANU Kotagede Yogyakarta

a. Tidak mendapatkan motivasi dari orang-orang terdekat(orang tua atau keluarga) 
Orang yang menghafal Al-Qur'an, pasti sangat membutuhkan motivasi dari orang-orang terdekat, kedua orang tua, keluarga dan sanak kerabat tentunya. Dengan adanya motivasi, ia akan lebih bersemangat dalam menghafalkan Al-Qur'an.

b. Belum Istiqamah

Seorang hafidz akan mengalami kesulitan dalam menjalani proses menghafal Al-Qur'an, tidak ada yang sanggup melakukannya kecuali orang yang memiliki keistiqamahan yang tinggi dan tekad yang kuat serta keinginan yang membaja dan layaknya orang yang siap mencapai sebuah kesuksesan. Dibawah ini adalah hasil angket tentang sikap keistiqamah dan kesungguh-sungguhan santri dalam muraja'ah hafalan Al-Qur'an.

Hafal Al-Qur'an merupakan anugerah agung yang harus disyukuri. Supaya anugerah ini tidak dicabut oleh Allah, termasuk salah satu cara mensyukurinya adalah dengan menjaga hafalan tersebut. Untuk menjaga hafalan itu dilakukan dengan cara menggunakan metode muraja'ah, yaitu sering mengulang yang sudah pernah dihafalkan. Metode mengulang ini bisa dilaksanakan sendiri, ataupun dengan temannya. Metode ini sangat membantu, sebab terkadang kalau mengulang sendiri terdapat kesalahan yang tidak disadari. Akan berbeda jika melibatkan teman, kesalahankesalahan yang terjadi akan mudah diketahui dan kemudian diperbaiki dibawah ini adalah hasil angket tentang keistiqamahan dalam muraja'ah.

c. Meluangkan waktu setelah shalat fardhu untuk muraja'ah hafalan AlQur'an

Diantara penghafal Al-Qur'an ada memproses hafalannya secara spesifik, yakni tidak ada kesibukan lain kecuali menghafal Al-Qur'an saja. Penghafal harus mampu mengantisipasi dan memilih waktu yang dianggap sesuai dan tepat baginya untuk menghafal Al-Qur'an.

Para psikolog mengatakan, bahwa manajemen waktu yang baik akan berpengaruh besar terhadap pelekatan materi pada ingatan, utamanya dalam hal ini bagi mereka yang mempunyai kesibukan lain. Dibawah ini adalah hasil angket tentang meluang kan waktu untuk muraja'ah hafalan Al-Qur'an setelah shalat fardhu.

d. Malas bermuraja'ah 
Rasa malas merupakan hambatan yang paling banyak ditemui para calon Hufadz di saat meghafal Al-Qur'an. Sifat ini seakan-akan sulit dihilangkan dari seorang penghafal Al-Qur'an. Begitu juga santri Madrasah Nurul Ummah kebanyakan pada saat akan muraj'ah, santri ini merasakan sifat yang malas, sehingga sifat ini sangat menghambat perjalanan seorang calon tahfidz yang akan menambah ataupun memuraja'ah (mengulang) hafalannya. Hal ini sama halnya yang dirasakan salah satu santri MANU. Ini dalah ungakapan dari Surya Dwi Saputra "Aku malas banget mas, jika aku mau muraja'ah hafalan,ku, apalagi kalau mau memuraja'ah (mengulang) hafalanku yang sudah pernah aku hafalkan lupa lagi, rasa malas itu tiba-tiba muncul dihatiku “.

Hal yang sama diungkapkan oleh Khairatul Faizah "Untuk menghafal ataupun memuraja'ah (mengulang) hafalan, saya tergantung dengan suasana hati mbak ida, jika suasana hati sedang tenang saya semangat untuk menghafal, tapi kalau hati sedang nggak enak, saya males banget mau menghafal Al-Qur'an.

e. Ayat-ayat yang sudah dihafalkan lupa lagi

Salah satu faktor penghambat yang dialami oleh seorang penghafal Al-Qur'an yaitu lupa lagi ayat-ayat yang sudah dihafalnya. Sebagaimana problem ini yang dialami oleh santri Madrasah Nurul Ummah santri yaitu sebagaimana yang diungkapkan oleh Surya Dwi Saputra kepada peneliti bahwa: "Iya mas, saya sudah muraja'ah tapi saya ngulang lagi ternyata masih banyak ayat yang lupa mas. Mungkin hal itu memang dari kesalahan saya sendiri lawong menghafal Al-Qur'an itu bukan hal yang mudah kog saya tidak muraja'ah berkali-kali ya begitu lah mas hasilnya”. Hal senada diungkapkan oleh Laili Khafifah Fauziah kepada peneliti bahwa: "Saya kadang-kadang malas mas, jenuh dan kadang-kadang marah pada diri saya sendiri mas, karena ayat-ayat yang sudah hafal kok lupa lagi padahal saya sering muraja'ah mas. Hal senada juga disampaikan oleh Ustadzah sri Wahyu Ningsih, bahwa : ketika setoran hafalan santri-santri sering lupa dari hafalan Al-Qur'an yang sudah dihafalkan, tapi kalau saya tegur dan saya sambung ayat yang tadinya lupa pasti santrinya langsung 
ingat dan langsung melanjutkan hafalannya, kebanyakan santri sering seperti itu.

\section{Upaya Santri dalam Pemeliharaan Hafalan Al-Qur'an}

1. Motivasi dari orang tua atau keluarga

Orang yang menghafal Al-Qur'an, pasti sangat membutuhkan motivasi dari orang-orang terdekat, kedua orang tua, keluarga dan sanak kerabat tentunya. Dengan adanya motivasi, ia akan lebih bersemangat dalam menghafalkan Al-Qur'an. hasil yang diperoleh akan berbeda jika motivasi yang di dapatkan kurang, hal ini bisa diketahui melalui ungkapan Surya Dwi Saputra tentang upaya selalu temotivasi : "Saya jarang dimotivasi oleh bapak atau ibu saya, mas, saya senang jadi hafizd qur'an mas yang sering memotivasi saya adalah sepupuh saya yang lagi mondok. Meskipun orang tua saya jarang memotivasi saya, saya tetap semangat mas Karna saya sering berteman dengan teman-teman yang hafalannya udah banyak, jadi itulah yang membuat saya jadi semangat”. Sebagaimana juga yang telah dikatakan oleh Laili Khofiofah Fauziah : "Saya hanya memotivasi diri saya sendiri mas dengan cara sering melihat teman-teman saya yang hafalannya sudah banyak, itulah yang membuat saya termotivasi. Dalam hati saya, teman-teman saya bisa mengapa saya tidak bisa.”

Saat muraja'ah hafalan Al-Qur'an, akan mengalami masalah yang monoton, gangguan, dan cobaan dari berbagai arah. Terkadang ujian ini membuat para penghafal bisa berpaling dari hafalannya.oleh karena itu harus adanya motivasi dari orang tua atau keluarga, Sebagaimana yang disampaikan Ustadzah Triwahyu Ningsih : Ada 2 faktor yang mempengaruhui hafalan, yaitu motivasi guru dan orang tua serta doa sebagai faktor nonteknis. Sedangkan adanya buku prestasi menjadi faktor pendukung secara teknisnya.

2. Upaya untuk meluangkan waktu setelah shalat fardhu untuk muraja'ah hafalan Al-Qur'an

Diantara penghafal Al-Qur'an ada memproses hafalannya secara spesifik, yakni tidak ada kesibukan lain kecuali menghafal Al-Qur'an saja. Penghafal harus mampu mengantisipasi dan memilih waktu yang 
dianggap sesuai dan tepat baginya untuk menghafal Al-Qur'an diantaranya selepas shalat fardhu 5 waktu. psikolog mengatakan, bahwa manajemen waktu yang baik akan berpengaruh besar terhadap pelekatan materi pada ingatan, utamanya dalam hal ini bagi mereka yang mempunyai kesibukan lain. Sebagaimana yang dukatakan oleh Surya Dwi Saputra sebagai berikut ini : "Saya jarang sekali mas, meluangkan waktu pada saat setelah sahalat Fardhu 5 waktu, padahal sangat apik mas, kalau kalu saya luangkan sebentar untuk menghafal atau muraja'ah 5-6 ayat. Dan yang saya lakukan isnya Allah bermuraja'ah 5-6 ayat setelah shalat, itu juga cuma sebentar kok mas." Senada juga yang dikatakan oleh Khairatul Faizah, berikut ini : "Saya jarang muraja'ah mas, apalagi setelah shalat fardhu, sebenarnya bagus si mas, kalau setelah shalat saya hafalkan atau muraja'ah 3 atau 4 ayat saja, andaikan 3 kali saja sudah lumayan, kalau dikalikan dengan 5 shalat wajib sehari semalam berarti 15 ayat sehari mas.” Sebagaiman juga yang disampaikan oleh Ustasza triwahyu Ningsih kepada peneliti bahwa : “ santri kadang-kadang kebingungan mengatur waktu untuk untuk menghafal atau muraja'ah hafalan Al-Qur'an. Itu yang membuat santri tidak konsisten dalam menghafal atau muraja'ah, tapi sekarang kami sudah punya jadwal khusus untuk santri yang menghafal Al-Qur’an.

3. Upaya untuk Istiqamah

Seorang hafidz akan mengalami kesulitan dalam menjalani proses menghafal Al-Qur'an, tidak ada yang sanggup melakukannya kecuali orang yang memiliki keistiqamahan yang tinggi dan tekad yang kuat serta keinginan yang membaja dan layaknya orang yang siap mencapai sebuah kesuksesan. Dibawah ini adalah upaya untuk tetap istiqamah dan kesungguh-sungguhan yang diungkapkan oleh Laili Khofifah Fauziah : "Sekarang saya jarang istiqamah mas, sebelumnya saya sangat istiqamah, saya biasanya menghafalkannya pagi ini sekitar setengah lembar dan sepulang sekolah muraja'ah hafalan yang tadi saya hafal tadi pagi kemudian entar malan muraja'ah lagi”. Khairatul Faizah juga mengatakan : "Saya gak pernah istiqamah mas, saya kadang muraja'ah kadang-kadang gak mas, agar saya selalu istiqamah adalah harus ada peraturannya hari 
ini umpamanya harus hafal 5 atau 6 ayat begitu kan apik mas, jadi saya bisa konsisten.”

4. Upaya mengatasi rasa malas

Salah satu faktor penghambat yang dialami oleh seorang penghafal Al-Qur'an yaitu lupa lagi ayat-ayat yang sudah dihafalnya. Sebagaimana problem ini yang dialami, untuk mengatasinya sebagai berikut yang disampaikan oleh Laili Khofifatul Fauziah kepada peneliti bahwa: "Saya kalau saat malas muraja"ah ialah saya selalu berpindah tempat atau ngobrol ma temen-teman sebentar kemudian saya muraja'ah lagi atau seumpamanya di tempat yang sepi, agar tidak jenuh, kalau jenuh mas pasti aku malas mau muraja'ah”. Hal senada diungkapkan oleh Khairatul Faizah kepada peneliti bahwa: "Saya pernah merasa malas mas, saat aku hafal tapi gak masuk-masuk juga mas, jadi jenuh dan kadang-kadang marah pada diri sendiri karena hafalan yang dihafalkan lupa lagi”.

5. Upaya mengatasi ayat-ayat yang sudah dihafalkan lupa lagi

Salah satu faktor penghambat yang dialami oleh seorang penghafal Al-Qur'an yaitu lupa lagi ayat-ayat yang sudah dihafalnya. Sebagaimana problem ini yang dialami oleh santri yaitu sebagaimana yang diungkapkan oleh Surya Dwi Saputra : "Sering lupa dengan ayat Al-Qur'an yang sudah dihafal tapi yang saya lakukan adalah saya sering membacanya saat shalat sunnah seperti shalat sunnah rawatib dan saya sehari kadang-kadang muraja'ahnya sekitar satu juz". Senada juga apa yang disampaikan Laili Khofifah Fauzia kepada peneliti bahwa : "Saya sering lupa mas, tapi saya terus muraja'ah karena saya sudah berusah dengan sekuat dan semampu saya, Insya Allah, Allah akan memberi yang terbaik untuk saya dan hasilnya lumayan memuaskan buat saya mas.”

\section{Penutup}

Siswa santri Madrasah Aliyah Nurul Ummah Kotagede Yogyakarta selalu melakukan hafalan Qur'an dengan target tiap hari adalah satu halaman tanpa menghitung berapa ayat yang dihafalkan. Metode muraja'ah dimaksudkan untuk menjaga hafalan Al-Qur'an yang sudah dihafalkan oleh para siswa santri tidak hilang. Kegiatan itu tidak mengganggu kegiatan belajar mengajar di pesantren. 
Muraja'ah dengan Melihat Al-Qur'an dapat bermanfaat membentuk keluwesan lidah dalam membaca, sehingga terbentuk suatu kemampuan spontanitas pengucapan. Selama proses belajar, penguacapa bersuara secara tidak langsung telah melatih mulut dan pendengarannya dalam melafalkan serta mendengarkan bacaannya sendiri. Ia pun akan akan bertambah semangat dan terus berupaya melakukan pembenaranpembenaran ketika terjadi salah pengucapan. Murajaahnya kepada ustadz atau ustadzah juga menjadi salah satu adalah cara untuk mengetahui hasilnya, apakah ia sudah lancar dalam menghafal atau belum.

\section{E. Daftar Pustaka}

Abdurrachman Mas'ud dkk, Dinamika pesantren dan madrasah, Yogyakarta : Pustaka Pelajar, 2002.

Herry, Bahirul Amalia Agar Orang Sibuk Bisa Menghafal Al-Qur'an, Yogyakarta: Pro-U Media, 2012.

Departemen Agama RI. Al-Qur'an dan Terjemahannya, Semarang :Toha Putra, 1989

Gus Arifin dan Suhendri Abu Faqih, Al-Qur'an Sang Mahkota Cahaya. Jakarta: PT Elex Media Komputindo, 2010

Al-Hafizh, Majdi Ubaid. 9 Langkah Mudah Menghafal Al-Qur'an, Solo: PT Aqwaf Media Profetika, 2015

Miftah Faridl dan Agus Syihabudin, Al-Qur'an Sumber Hukum Islam Yang Pertama, Bandung: Pustaka, 1989

Sugiyono, Metode Penelitian Pendidikan. Bandung: alfabeta, 2012.

Nuwabuddin, Abd Ar-Rabb. Metode Praktis Hafal Al-Qur'an, Jakarta: Pustka Firdaus, 1991.

Sutrisno Hadi, Metodelogi Research, Yogyakarta: Andi Offset, 1997

Ash-shiddieqy, TM Hasbi. Ilmu Al-Qur'an dan Tafsir. Semarang: PT Pustaka Rizki Putra, 1997 
Ahlan Abdullah Solo, Taufik Nugroho \& Difla Nadjih 